\title{
Dysphagia progression-free survival in oesophageal cancer patients treated with palliative radiation therapy
}

\begin{tabular}{|c|c|}
\hline $\begin{array}{l}\text { Authors: } \\
\text { Nazreen Bhim } \\
\text { Visham Bhaga } \\
\text { Alistair Hunter } \\
\text { Galya Chinner } \\
\text { Barbara Rober }\end{array}$ & $\begin{array}{l}1,2 \text { (1) } \\
\mathrm{OO}^{1,2} \text { (1) } \\
\operatorname{tson}^{1,3} \text { (1) }\end{array}$ \\
\hline \multicolumn{2}{|c|}{$\begin{array}{l}\text { Affiliations: } \\
{ }^{1} \text { Department of Radiation } \\
\text { Oncology, Groote Schuur } \\
\text { Hospital, Cape Town, } \\
\text { South Africa }\end{array}$} \\
\hline \multicolumn{2}{|c|}{$\begin{array}{l}{ }^{2} \text { Faculty of Health Sciences, } \\
\text { University of Cape Town, } \\
\text { Cape Town, South Africa }\end{array}$} \\
\hline \multicolumn{2}{|c|}{$\begin{array}{l}{ }^{3} \text { Department of Surgery, } \\
\text { Groote Schuur Hospital, } \\
\text { Cape Town, South Africa }\end{array}$} \\
\hline \multicolumn{2}{|c|}{$\begin{array}{l}\text { Corresponding author: } \\
\text { Nazreen Bhim, } \\
\text { nazreenbhim@gmail.com }\end{array}$} \\
\hline \multicolumn{2}{|c|}{$\begin{array}{l}\text { Dates: } \\
\text { Received: } 21 \text { Feb. } 2021 \\
\text { Accepted: } 06 \text { Apr. } 2021 \\
\text { Published: } 30 \text { June } 2021\end{array}$} \\
\hline \multicolumn{2}{|c|}{$\begin{array}{l}\text { How to cite this article: } \\
\text { Bhim N, Bhagaloo V, } \\
\text { Hunter A, Chinnery G, } \\
\text { Roberson B. Dysphagia } \\
\text { progression-free survival in } \\
\text { oesophageal cancer patients } \\
\text { treated with palliative } \\
\text { radiation therapy. S. Afr. j. } \\
\text { oncol. 2021;5(0), a171. } \\
\text { https://doi.org/10.4102/sajo. } \\
\text { v5i0.171 }\end{array}$} \\
\hline \multicolumn{2}{|c|}{$\begin{array}{l}\text { Copyright: } \\
\text { (C) 2021. The Author(s). } \\
\text { Licensee: AOSIS. This wor } \\
\text { is licensed under the } \\
\text { Creative Commons } \\
\text { Attribution License. }\end{array}$} \\
\hline \multicolumn{2}{|l|}{ Read online: } \\
\hline 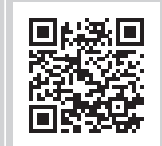 & $\begin{array}{l}\text { Scan this QR } \\
\text { code with your } \\
\text { smart phone or } \\
\text { mobile device } \\
\text { to read online. }\end{array}$ \\
\hline
\end{tabular}

Background: In patients with advanced oesophageal carcinoma, palliation of dysphagia is important to maintain a reasonable quality of life.

Aim: To determine the dysphagia progression-free survival (DPFS) in patients with advanced oesophageal carcinoma treated with palliative radiotherapy (RT).

Setting: Groote Schuur Hospital, Cape Town, between January 2015 and December 2016.

Methods: The medical records of all patients with oesophageal carcinoma were reviewed, and patients who were not candidates for curative treatment and received palliative RT were selected. For these patients, the dysphagia score (DS) was recorded prior to RT, six weeks after RT and at each follow-up visit. The DPFS was calculated as the time from completion of RT to worsening of DS by $\geq 1$ point or until death. Other outcomes measured were objective change in DS and survival post RT.

Results: The study population comprised 84 patients. Squamous cell cancer was the primary histological subtype (93\%). The median duration of DPFS after RT was 73 days, with approximately two-thirds of remaining patients able to swallow at least liquids and soft diet until death. The difference in median duration of DPFS was not statistically significant in stented versus non-stented patients ( 54 days vs 83 days, $p=0.224$ ). The mean change in DS was $0.45 \pm 0.89$ points following RT and the post-RT survival was significantly shorter in patients with stent insertion (81 days vs 123 days, $p=0.042$ ).

Conclusion: Palliative RT can successfully be used to prolong DPFS in patients with locally advanced and metastatic squamous cell cancer of the oesophagus.

Keywords: oesophageal cancer; locally advanced; dysphagia score; palliative radiotherapy; squamous cell cancer.

\section{Introduction}

In 2018, approximately 572000 new cases of oesophageal cancer were diagnosed worldwide, and this was the seventh most common cancer diagnosed in South Africa. ${ }^{1,2,3}$ Approximately $70 \%$ of cases in England, Scotland and Northern Ireland in 2014 were diagnosed at a late stage. ${ }^{1}$ Although definitive data are lacking for South Africa, most new cases follow a similar trend, with a high percentage of patients presenting with locally advanced or metastatic disease. One retrospective study conducted in South Africa by Dandara et al. ${ }^{4}$ examining all patients presenting with oesophageal cancer over a 30 -year period reported that $76 \%$ of patients presented with advanced disease and poor clinical condition requiring palliative care. ${ }^{4}$ In those patients receiving palliative care, the average survival was approximately $4-6$ months. ${ }^{4,5}$

Dysphagia is documented as the most common presenting symptom, prompting patients with oesophageal cancer to seek medical care and has a substantial impact on quality of life which becomes more significant in advanced disease. ${ }^{6,7}$ One large study conducted by the American College of Surgeons ${ }^{8}$ reported dysphagia in $74 \%$ of the 5044 patients enrolled. Palliation of this symptom is crucial to maintain an acceptable quality of life in these patients. ${ }^{9,10,11}$

Currently no consensus guidelines are available for the optimal management of dysphagia in patients with locally advanced and metastatic oesophageal cancer. Options for palliation include stent placement, dilatation, external beam radiotherapy (RT), brachytherapy, chemotherapy, laser treatment, and photodynamic therapy or ablation. ${ }^{12,13}$ Various studies have been carried out comparing the benefit of RT, both external beam radiotherapy (EBRT) and brachytherapy to 
endoscopic stenting while evaluating various end points to determine the efficacy of treatment. Retrospective studies demonstrated that endoluminal stenting that provided earlier and more rapid relief of symptoms, however, was associated with recurrent dysphagia in the long-term ${ }^{11}$ while RT provides more durable response. ${ }^{14}$ These studies suggested the optimal management for palliation of dysphagia in these patients is a combination of endoluminal stenting and RT or brachytherapy. $13,14,15,16$ Palliative chemoradiation shows a modest but not significant benefit over RT alone ${ }^{17}$; and considering the increased toxicity associated with concurrent chemoradiation, it is not considered a viable option in palliation. Although previous data suggest effective relief of dysphagia in patients with locally advanced and metastatic oesophageal cancer treated with palliative RT, ${ }^{5}$ only limited data are available to suggest the duration of this response. One retrospective study of the use of RT in palliation of dysphagia conducted in the Netherlands by Caspers et al. ${ }^{18}$ reports improvement in dysphagia score (DS) in $70.5 \%$ of patients with a median dysphagia-free interval of 3.7 months. Another retrospective study conducted in Germany by Welsch et al. ${ }^{19}$ between 1994 and 2004, analysing 139 patients with advanced or incurable oesophageal cancer treated with palliative RT, that is, with EBRT, brachytherapy or a combination of both EBRT and brachytherapy, reported subjective symptom relief in $72 \%$ of patients with a median response duration of five months. ${ }^{19}$ Our study was primarily aimed at examining the overall duration of response to RT in our clinical setting and to identify the contributing factors that may affect the overall response to palliative RT.

\section{Methods \\ Study aims and objectives}

The aim of this study was to assess the benefits of palliative RT in the management of patients with locally advanced and metastatic oesophageal cancer at a single institution.

The primary objective was to determine the median dysphagia progression-free survival (DPFS) after RT in patients with locally advanced or metastatic oesophageal cancer. The secondary objectives were to compare the duration of DPFS in patients with and without oesophageal stenting to determine the overall quantitative objective improvement in DS after receiving palliative RT in patients with advanced oesophageal cancer and to determine the median overall survival (OS) and post-RT survival of patients following palliative RT.

\section{Study population}

The records of all new patients who presented with oesophageal cancer to the gastro-oesophageal oncology clinic at Groote Schuur Hospital, Cape Town, between January 2015 and December 2016 were reviewed. Only patients with stage I-III oesophageal cancer, who were not candidates for the potentially curative treatment (i.e. not physiologically fit, tumours involving adjacent organs or multi-station and bulky lymphadenopathy), or with stage IV disease were selected. Further inclusion criteria were patients determined to have a DS of 1-4 at initial visit or during follow-up using the Knyrim et al. ${ }^{20}$ dysphagia grading system (see Appendix 1 ) and were treated with palliative radiation. Patients who were less than 18 years of age, had received chemotherapy for carcinoma of the oesophagus, had percutaneous endoscopic gastrostomy insertion or patients with tracheo-oesophageal fistulae were excluded from the study.

\section{Scientific design}

This was a retrospective, observational study. The patients meeting the inclusion criteria were selected for further data collection and analysis.

\section{Treatment}

All patients were reviewed in the gastro-oesophageal multidisciplinary team meeting for a treatment decision. Patients were selected for palliative treatment based on the characteristics at presentation such as poor Eastern Cooperative Oncology Group performance status (PS [ECOG]), significant weight loss $\geq 10 \%$ baseline body weight, low body mass index (BMI), multiple medical comorbidities and poor general clinical condition. Because of the limited resources, only patients who were being considered for curative treatment were staged with computed tomography (CT) scan of the chest, abdomen and pelvis. All patients who presented with DS grade 3 or 4 were referred to the upper gastroenterology surgical service for assessment of stent insertion. They were reviewed post-stent insertion; an updated DS was assigned based on the current clinical status and they were assessed for palliative RT. The palliative RT was offered to patients who had significant symptoms such as dysphagia and odynophagia and were in reasonable clinical condition. The aim was to maintain swallowing and control pain,, whereas patients whose general condition was too poor that the palliative RT was thought not to add any benefit were supportively treated.

The choice of fractionation schedule was at the radiation oncologist's discretion and three fractionation regimes were used at our centre, namely, $4.6 \mathrm{~Gy} \times 4 \#$ (Equivalent dose in 2 Gy fractions [EQD2 = 28.0 Gy]), $4.0 \mathrm{~Gy} \times 5 \#(\mathrm{EQD} 2=28.0$ Gy) or 3.0 Gy $\times 10 \#(E Q D 2=36.0 \mathrm{~Gy})$, assuming an alpha and beta ratio of 3 for late effects. Patient factors including socioeconomic were considered in deciding fractionation schedule; in general, the higher dose of RT was offered to patients were planned using 2-D simulation technique. The patients were positioned supine with head rest, knee and ankle stocks for immobilisation and an anterior image was taken. In patients with a stent in situ, the field was placed to encompass the stent and an additional $2 \mathrm{~cm}$ margin superiorly, inferiorly and laterally. In patients without a stent in situ, $10 \mathrm{~mL}$ of barium was given orally and a fluoroscopic image was taken to determine the site of the tumour. The field was then placed to encompass the lesion with an additional 5- $\mathrm{cm}$ margin superiorly, inferiorly and $2 \mathrm{~cm}$ laterally. The patients were treated with photons, either Cobalt-60 (Co-60) or 6 Megavoltage (MV) X-rays, once per day (Monday-Friday) with a treatment break on weekends. 
Patients were reassessed six weeks after completing RT and then routinely every three months or earlier if dysphagia worsens. The medical records of these patients were reviewed for objective worsening of DS at these visits. The DPFS was taken as the date from the completion of RT to worsening of DS by $\geq 1$ point. Patients who died without returning to follow up with complaint of increasing dysphagia were assumed to have DPFS from the time of radiation therapy until death. This information was used to calculate the median DPFS in the patient population and to compare the median DPFS in patients with and without stent insertions. The objective improvement in DS was calculated by determining the change in DS after RT for each patient. These values were used to determine the mean objective improvement in DS. The OS and post-RT survival were measured from the date of diagnosis and date of completion of RT, respectively, to the date of death.

\section{Statistical analysis}

Formal sample size calculations were not performed. The number of subjects was chosen based on the feasibility of data collection and was considered sufficient to meet the study objectives.

The data collected was stored in the REDCap (Research Electronic Data Capture) database and the interface was used to process the data and analyse the variables relevant to the study. The data collected using REDCap software was only accessible to the primary investigator and the student investigator.

Stata MP version 14 software was used for data processing and analysis. Continuous variables were presented as mean/ standard deviation (s.d.) or median/interquartile range (IQR) depending on data distribution. Continuous data were analysed using independent $t$ test or Mann-Whitney U test.

Kaplan-Meier survival analysis was performed to determine the DFPS, OS and post-RT survival; and log-rank test was performed to test for significant differences in the probability of survival by stent insertion. Time 0 was defined as the day the patient completed RT. To determine the variables associated with DPFS, change in DS and post-RT survival, multiple linear regression analysis was performed. The variables analysed were gender, age, PS(ECOG), DS at presentation, time of RT and post-RT, histological subtype, site of primary tumour, RT fractionation schedule, stent insertion and weight loss $>10 \%$ of baseline. Variables with $p<0.20$ in the univariate analysis (i.e. simple linear regression) were entered into the adjusted model. Model building was then performed using a backward elimination technique, and $p$-values $\leq 0.05$ were considered statistically significant. These results were displayed as charts and tables.

\section{Ethical considerations}

The study proposal was approved by the Human Research and Ethics committee of the Faculty of Health Sciences at University of Cape Town. HREF: 106/2018

\section{Results}

A total of 84 patients presenting to the gastro-oesophageal carcinoma clinic between the period January 2015 and December 2016 met the inclusion criteria for the study. The patient- and disease-specific factors were grouped by variables such as gender, age group, PS (ECOG), histological subtype and location of primary tumour are provided in Table 1.

A slight predominance of male patients 46 (54.8\%) versus female patients $38(45.2 \%)$ was observed. The mean age was 59 years and the modal age group was 51-60. More than $50 \%$ of all patients were between 50 and 70 years. No patients in our study population were younger than 31 years of age. Most patients were observed to have a PS (ECOG) 2 or 3. Regarding the duration of symptoms, most patients had symptoms for > 3-6 months prior to

TABLE 1: Demographics and disease-related variables in the study population.

\begin{tabular}{|c|c|c|}
\hline \multirow[t]{2}{*}{ Variable } & \multicolumn{2}{|c|}{ Patients } \\
\hline & $n$ & $\%$ \\
\hline \multicolumn{3}{|l|}{ Gender } \\
\hline Male & 46 & 54.8 \\
\hline Female & 38 & 45.2 \\
\hline \multicolumn{3}{|l|}{ Age group (years) } \\
\hline $18-24$ & 0 & 0.0 \\
\hline $25-30$ & 0 & 0.0 \\
\hline $31-40$ & 3 & 3.6 \\
\hline $41-50$ & 16 & 19.0 \\
\hline $51-60$ & 30 & 35.7 \\
\hline $61-70$ & 19 & 22.8 \\
\hline $71-80$ & 13 & 15.5 \\
\hline$>80$ & 3 & 3.6 \\
\hline \multicolumn{3}{|l|}{ Performance status (ECOG) } \\
\hline 0 & 0 & 0.0 \\
\hline 1 & 27 & 32.1 \\
\hline 2 & 33 & 39.3 \\
\hline 3 & 21 & 25 \\
\hline 4 & 3 & 3.6 \\
\hline \multicolumn{3}{|l|}{ Histological subtype } \\
\hline Squamous cell carcinoma & 78 & 92.9 \\
\hline Adenocarcinoma & 6 & 7.1 \\
\hline \multicolumn{3}{|l|}{ Location of primary tumour } \\
\hline Upper $1 / 3$ & 13 & 15.5 \\
\hline Middle $1 / 3$ & 46 & 54.8 \\
\hline Lower $1 / 3$ & 16 & 22.6 \\
\hline $\begin{array}{l}\text { Gastro-oesophageal } \\
\text { junction }\end{array}$ & 6 & 7.1 \\
\hline \multicolumn{3}{|l|}{ Duration of symptoms } \\
\hline$<1$ month & 1 & 1.2 \\
\hline$>1-3$ months & 22 & 26.2 \\
\hline$>3-6$ months & 34 & 40.5 \\
\hline $6-12$ months & 20 & 23.8 \\
\hline $1-2$ years & 6 & 7.1 \\
\hline$>2$ years & 1 & 1.2 \\
\hline \multicolumn{3}{|l|}{ Loss of weight } \\
\hline Yes & 73 & 86.9 \\
\hline No & 11 & 13.1 \\
\hline$<10 \%$ & 13 & 17.8 \\
\hline$>10 \%$ & 60 & 83.2 \\
\hline
\end{tabular}

ECOG, Eastern Cooperative Oncology Group. 
presentation; and the mean duration of symptoms was 6.1 months before seeking medical attention. The most common presenting symptoms were dysphagia and weight loss. More than $85 \%$ of patients had reported weight loss as shown in Table 1; of these $>75 \%$ reported losing more than $10 \%$ of their baseline body weight.

The most common histological subtype was squamous cell cancer (78 patients; 92.9\%) versus adenocarcinoma (6 patients; $7.1 \%)$. The most common subsite among all patients was the middle third of the oesophagus (46 patients; $54.8 \%$ ) followed by the lower third of the oesophagus (16 patients; $22.6 \%$ ). The least common subsite was the gastro-oesophageal junction (6 patients; $7.1 \%$ ).

More than $90 \%$ of the patients had a DS $\geq 2$ at presentation. Approximately half of the patients had insertion of oesophageal stent (43 patients, 51.2\%). Most patients presenting with DS $\leq 2$ did not have oesophageal stent insertion. Of the patients with grade 4 dysphagia who were referred for stent insertion, one failed to have the procedure because of poor PS (ECOG) (Table 2). After stent insertion, $100 \%$ of patients had an improvement in DS by $\geq 1$ point.

For the delivery of palliative RT, three fractionation regimens were used, namely, 18 (21\%) of patients received $20.0 \mathrm{~Gy}$ in $5 \#, 60(71 \%)$ received $18.4 \mathrm{~Gy}$ in $4 \#$ and $6(7 \%)$ received 30.0 Gy in $10 \#$.

The DS as assessed prior to starting RT, after RT and at the time of progression of dysphagia is shown in Figure 1. One patient was lost to follow-up and hence the data for the remaining 83 patients were analysed. Prior to RT, the

TABLE 2: Dysphagia score at presentation and in patients having stent insertion.

\begin{tabular}{lcccccc}
\hline Dysphagia score & \multicolumn{3}{c}{ Total } & & \multicolumn{2}{c}{ Stent insertion } \\
\cline { 2 - 3 } \cline { 5 - 6 } & $\boldsymbol{n}$ & $\mathbf{\%}$ & & Yes & No \\
\hline 0 & 2 & 2.4 & & 0 & 2 \\
1 & 5 & 6.0 & & 0 & 5 \\
2 & 40 & 47.6 & & 14 & 26 \\
3 & 22 & 26.2 & & 15 & 7 \\
4 & 15 & 17.9 & & 14 & 1 \\
\hline Total & $\mathbf{8 4}$ & - & & $\mathbf{4 3} \uparrow$ & $\mathbf{4 1}$ \\
\hline
\end{tabular}

$\dagger, 51.2 \% ; \ddagger 48.8 \%$

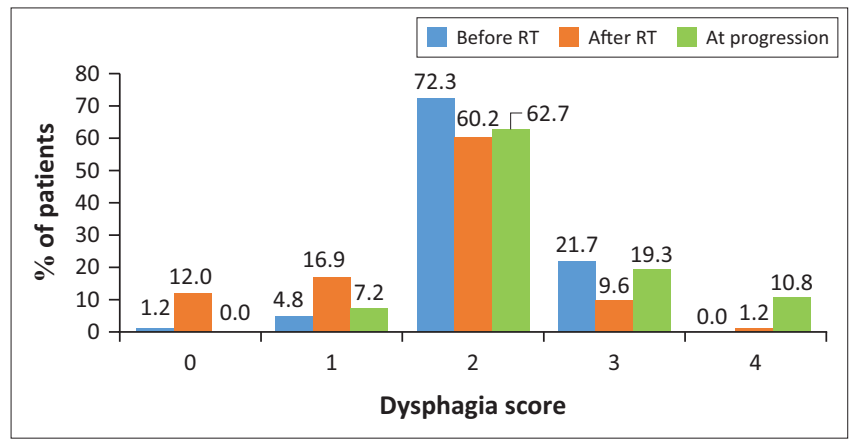

$\mathrm{RT}$, radiotherapy.

FIGURE 1: Bar chart showing Dysphagia score at various time intervals. majority of patients (94\%) had DS of grade 2 or 3 . Our study did not include any patients with grade 4 dysphagia at the time of RT as all patients seen post-stent insertion with DS of grade 4 either did not meet the inclusion criteria or died prior to receiving RT. At the post-RT review, 58 patients $(68.9 \%)$ had DS of grade 2 or 3 . One patient $(1.2 \%)$ had a deterioration in DS to grade 4 following RT.

The duration of DPFS is represented in the column chart (Figure 2) and scatter plot (Figure 3). The median DPFS calculated using the ungrouped data was 73 days (IQR: 35145) (Figure 4). Simple and multiple linear regression analyses were performed to assess the association between DPFS and several variables. The median DPFS appeared to have a numerically significant difference between those with and without stent insertion, with patients with a stent having a shorter duration of DPFS (median 54 days; [IQR: 31-98]) than those without a stent (median 83 days; [IQR: 45.5-176.5]) (Figure 5). However, this result in conjunction with the logrank test $(p=0.224)$ confirmed no statistical significance between DPFS in patients who were stented and those who were not.

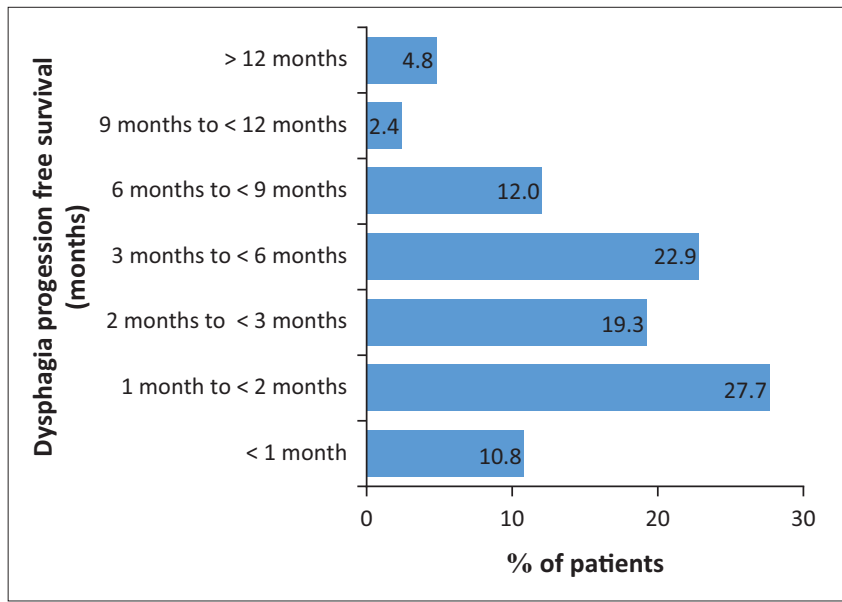

DPFS, dysphagia progression-free survival.

FIGURE 2: Duration of dysphagia progression free survival.

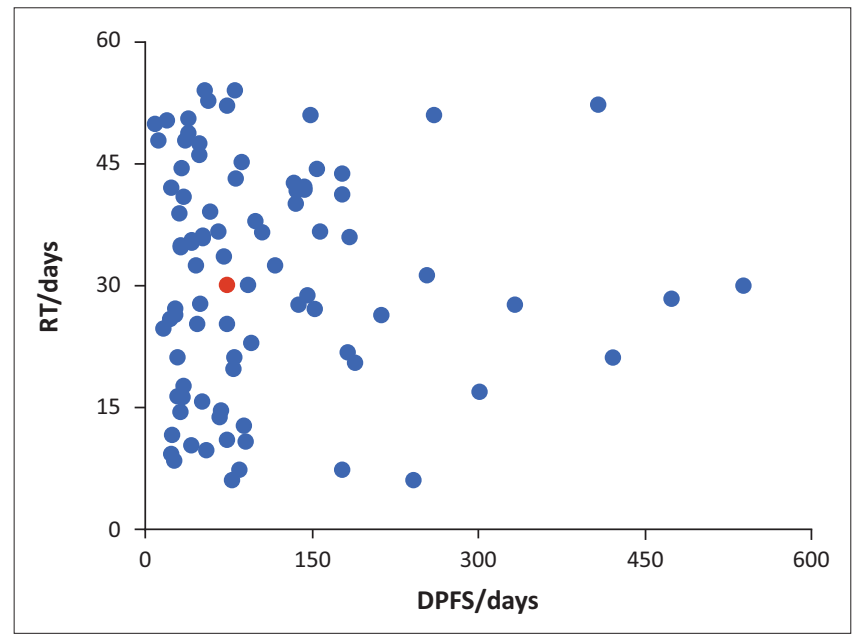

DPFS, dysphagia progression-free survival; RT, radiotherapy.

FIGURE 3: Scatterplot showing distribution of DPFS (ungrouped data). 


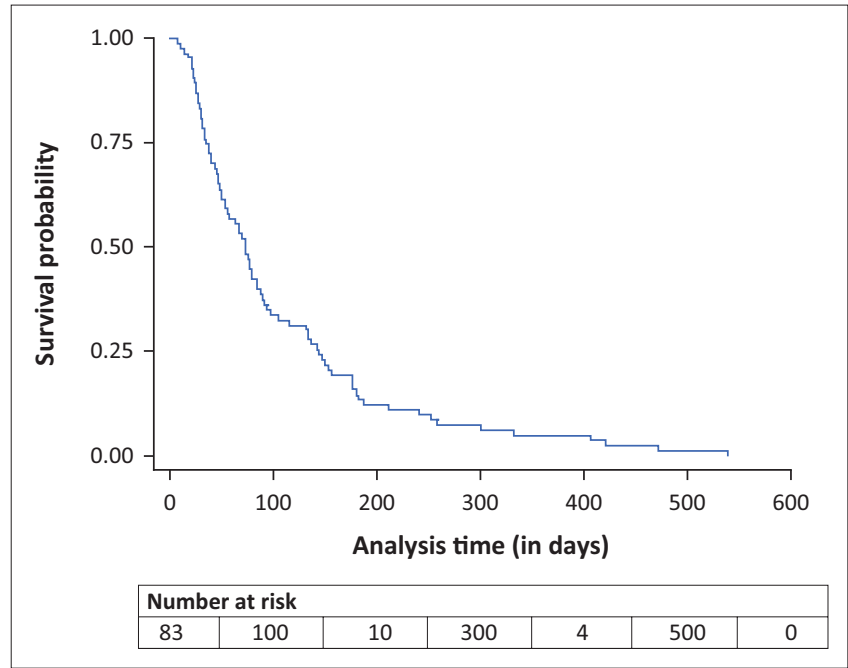

DPFS, dysphagia progression-free survival.

FIGURE 4: Kaplan-Meier survival estimate for DPFS in all patients who received palliative RT.

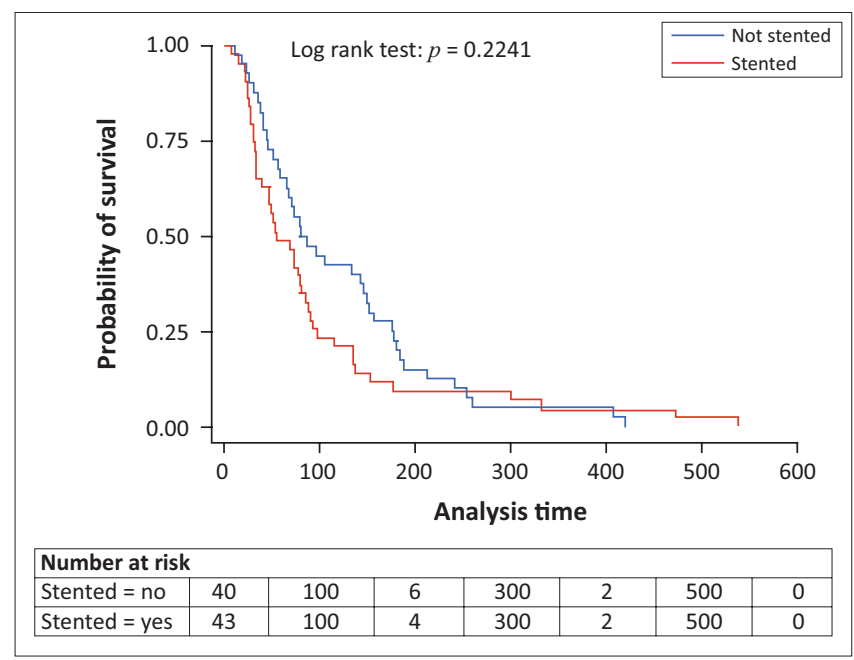

DPFS, dysphagia progression-free survival.

FIGURE 5: Kaplan-Meier survival estimates for DPFS in patients with or without stent insertion who received palliative RT.

A simple regression analysis showed the median duration of DPFS significantly differed by DS at presentation $(p=0.045)$, DS after RT $(p<0.0001)$ and PS (ECOG) $(p=0.036)$ (Table 3$)$. Using multiple linear regression, only the DS after RT $(p<0.0001)$ was found to be significantly associated with DPFS. From this analysis, for every 1 point increase in DS, the DPFS decreased by 61 days.

The objective changes in DS when reassessed at six weeks after palliative RT were as follows: 4 (4.8\%) of patients had worsening of DS, 48 (57.8\%) of patients had no change in DS from baseline; however, 31 patients $(37.3 \%)$ had an improvement in DS following RT; 21 patients (25.3\%) reported an improvement in DS by 1 point, 8 patients (9.6\%) reported an improvement by 2 points and 2 patients $(2.4 \%)$ reported an improvement by 3 points. The mean objective change in DS was $0.45 \pm 0.89$ points in all patients at six weeks post-RT treatment and $0.28 \pm 0.80$ points in stented and $0.63 \pm 0.95$ points in non-stented patients. Independent $t$ test showed that the difference in mean objective
TABLE 3: Simple linear regression analysis for variables associated with dysphagia progression-free survival.

\begin{tabular}{lccc}
\hline Variable & \multicolumn{3}{c}{ Simple linear regression analysis } \\
\cline { 2 - 4 } & Beta coeff. & $95 \% \mathrm{Cl}$ & $\boldsymbol{p}$ \\
\hline Stent insertion (Ref: No) & -24.26 & $-70.65-22.13$ & 0.301 \\
Age category (Ref: <60) & -6.12 & $-52.77-40.54$ & 0.795 \\
DS at presentation & -24.94 & $-49.25--0.63$ & $0.045^{*}$ \\
DS at time of RT & -40.33 & $-82.56-1.89$ & 0.061 \\
DS after RT & -60.88 & $-85.05--36.71$ & $<0.0001^{*}$ \\
PS (Ref: PS 1/2) & -53.66 & $-103.74--3.57$ & $0.036^{*}$ \\
Gender (Ref: Female) & -13.43 & $-60.17-33.31$ & 0.569 \\
Histology (Ref: SCC) & 42.43 & $-47.20-132.05$ & 0.349 \\
Site of tumour (Ref: Upper 1/3) & & & \\
Middle 1/3 & -13.25 & $-81.53-55.03$ & 0.700 \\
Lower 1/3 & 28.36 & $-49.31-106.02$ & 0.470 \\
GEJ & 54.08 & $-51.23-159.40$ & 0.310 \\
RT fractionation scheduled (Ref: 20.0 Gy/ 5\#) & & \\
18.4 Gy in 4\# & -32.94 & $-89.89-24.02$ & 0.253 \\
30 Gy in 10\# & -58.44 & $-158.15-41.26$ & 0.247 \\
Weight loss (Ref: No) & & & \\
Yes, $\leq 10 \%$ & 4.38 & $-85.58-94.3$ & 0.923 \\
Yes, > 10\% & 8.88 & $-64.17-81.93$ & 0.809 \\
\hline RT, ratiot & & & \\
\hline
\end{tabular}

$\mathrm{RT}$, radiotherapy; PS, performance status; GEJ, gastro-oesophageal junction; $\mathrm{Cl}$, confidence interval; coeff., coefficient.

*, Statistically significant.

TABLE 4: Simple linear regression analysis for variables associated with mean objective change in dysphagia score.

\begin{tabular}{lccc}
\hline Variable & \multicolumn{3}{c}{ Simple linear regression analysis } \\
\cline { 2 - 4 } & Beta coeff. & $95 \% \mathrm{Cl}$ & $p$ \\
\hline Stent insertion (Ref: No) & -0.35 & $-0.73-0.04$ & 0.076 \\
DS at presentation & -0.03 & $-0.24-0.18$ & 0.776 \\
DS at time of RT & 0.56 & $0.22-0.90$ & $0.001^{*}$ \\
PS (Ref: PS 1/2) & -0.16 & $-0.59-0.27$ & 0.465 \\
Histology (Ref: SCC) & -0.12 & $-0.87-0.63$ & 0.749 \\
Site of tumour (Ref: Upper 1/3) & & & \\
Middle 1/3 & -0.004 & $-0.58-0.58$ & 0.990 \\
Lower 1/3 & 0.16 & $-0.50-0.82$ & 0.626 \\
GEJ & -0.08 & $-0.98-0.81$ & 0.854 \\
RT fractionation scheduled (Ref: 20.0 Gy/5\#) & & \\
18.4 Gy in 4\# & -0.17 & $-0.65-0.30$ & 0.477 \\
30 Gy in 10\# & -0.61 & $-1.44-0.22$ & 0.147 \\
Weight loss (Ref: No) & & & \\
Yes, $\leq 10 \%$ & 0.32 & $-0.43-1.06$ & 0.404 \\
Yes, > 10\% & 0.13 & $-0.47-0.74$ & 0.663 \\
\hline
\end{tabular}

DS, dysphagia score; RT, radiotherapy; PS, performance status; GEJ, gastro-oesophageal junction; $\mathrm{Cl}$, confidence interval; coeff., coefficient.

*, Statistically significant.

change in DS between the stented and non-stented groups was not statistically significant ( $p=0.0757)$.

Simple regression analysis showed DS at time of RT was the only variable significantly associated with the mean objective change in DS ( $p=0.001)$ (Table 4$)$. Using multiple linear regression, only the DS at the time of RT ( $p=0.001)$ was found to be significantly associated with DS. From this analysis, for every 1 point increase in DS at the time of RT, the mean objective change post RT decreased by 0.56 points.

The median OS of patients receiving RT was 150 days (IQR: 131-169). The median OS in the RT patients without stents was 154 days (IQR: 99-211) while the median OS in the RT 
TABLE 5: Simple linear regression analysis for variables associated with postradiotherapy survival.

\begin{tabular}{|c|c|c|c|}
\hline \multirow[t]{2}{*}{ Variable } & \multicolumn{3}{|c|}{ Simple linear regression analysis } \\
\hline & Beta coeff. & $95 \% \mathrm{Cl}$ & $p$ \\
\hline Age category (Ref: <60) & -5.04 & $-57.67-47.60$ & 0.849 \\
\hline DS at presentation & -30.52 & $-57.54--3.49$ & $0.027 *$ \\
\hline DS at time of RT & -43.85 & $-90.97-3.27$ & 0.068 \\
\hline Change in DS & 39.73 & $11.49-67.97$ & $0.006 *$ \\
\hline PS (Ref: PS 1/2) & -61.65 & $-117.67--5.69$ & $0.031 *$ \\
\hline Gender (Ref: Female) & -13.35 & $-66.10-39.41$ & 0.616 \\
\hline Histology (Ref: SCC) & 41.86 & $-67.11-150.83$ & 0.447 \\
\hline \multicolumn{4}{|c|}{ Site of tumour (Ref: Upper 1/3) } \\
\hline Middle $1 / 3$ & -3.64 & $-79.86-72.57$ & 0.924 \\
\hline Lower $1 / 3$ & 38.94 & $-48.48-126.38$ & 0.378 \\
\hline GEJ & 76 & $-41.29-193.29$ & 0.201 \\
\hline \multicolumn{4}{|c|}{ RT fractionation scheduled (Ref: $20.0 \mathrm{~Gy} / 5 \#$ ) } \\
\hline $18.4 \mathrm{~Gy}$ in $4 \#$ & -30.11 & $-95.45-35.23$ & 0.362 \\
\hline 30Gy in 10\# & -44.26 & $-156.77-68.24$ & 0.436 \\
\hline \multicolumn{4}{|l|}{ Weight loss (Ref: No) } \\
\hline Yes, $\leq 10 \%$ & 46.73 & $-55.96-149.43$ & 0.368 \\
\hline Yes, > $10 \%$ & 12.79 & $-71.97-97.54$ & 0.765 \\
\hline
\end{tabular}

DS, dysphagia score; RT, radiotherapy; PS, performance status; GEJ, gastro-oesophagea junction; $\mathrm{Cl}$, confidence interval; coeff., coefficient.

*, Statistically significant.

patients with stents was 136 days (IQR: 71-206). The difference between these values compared by Mann-Whitney $\mathrm{U}$ test was not statistically significant $(p=0.387)$.

The median survival following RT in the study population was 95 days (IQR: 41-154). In the stented group of patients, the median survival was 81 days (IQR: 30-135) compared to 123 days (IQR: 58-181) in the non-stented group of patients. The Mann-Whitney $U$ test was used to assess the correlation between post-RT OS and stent insertion and showed that median survival post-RT was significantly shorter in patients who had a stent insertion $(p=0.0482)$.

Simple regression analysis showed that the only variables which significantly affected post-RT OS were DS at presentation ( $p=0.027)$, change in DS post RT $(p=0.006)$ and PS (ECOG) $(p=0.031)$ (Table 5). Using multiple linear regression, DS at presentation $(p=0.002)$ and change in DS post RT $(p<0.0001)$ were found to be significantly associated with post-RT OS. From this analysis, for every 1 unit increase in DS at the time of RT, the duration of post-RT survival decreases by 75 days, holding other variables constant and for every 1 unit increase in the change in DS, the duration of post-RT survival increases by 56 days, holding other variables constant.

\section{Discussion}

From our study, the median DPFS after palliative RT was 73 days; the median DPFS in patients without stent insertion was approximately 1 month longer than that in the stented subgroup of patients (83 days vs 54 days); however, this result was not statistically significant between the two groups $(p=0.224)$. Patients having DS 1 or 2 at presentation or post-RT or PS (ECOG) $\leq 2$ had significantly better DPFS. No other variables were associated with DPFS.
Because of the assumption that patients who died were considered to have had dysphagia progression at the time of death, the estimated value for median DPFS in our study represents the worst-case scenario and is most likely to represent a minimum value as the cause of death may not directly be related to failure to swallow in these patients.

Following palliative RT, the median change in DS was 0, with most patients $(57.8 \%)$ remaining unchanged following treatment. The mean objective change in DS was calculated as $0.45 \pm 0.89$ points. This value is much lower than that described in studies examining the impact of stent insertion as the sole intervention ${ }^{5}$ which suggests that patients receiving RT have a less dramatic improvement in dysphagia than patients who have stent insertion. Existing literature reports approximately $60 \%-70 \%$ of patients have improvement in DS immediately following stent insertion. ${ }^{14,21,22}$ The relief of dysphagia following RT is slower usually taking approximately 4-6 weeks to improve post RT. ${ }^{11,23}$ From our data, at 6 weeks post RT, only $37.5 \%$ of patients reported improvement in DS, thus supporting previous data that stenting provides a more rapid relief of dysphagia than RT.

In our study population, the median OS was 150 days, the median OS in the RT patients without stents was 154 days while the median OS in the RT patients with stents was 136 days. Previous data suggested the median OS to be 62 days in patients with only covered stent insertion. ${ }^{10}$ Thus, our data suggest that the RT with or without stenting leads to an improved median OS.

The median post-RT survival in the study population was 95 days. The post-RT survival was significantly longer in the non-stented group than in the stented group of patients (123 vs. 81 days; $p=0.0482)$. Both PS (ECOG $\leq 2)$ and DS $\leq 2$ at presentation and after RT were significantly associated with improved median post-RT survival on simple linear regression analysis. Using the DPFS curve for all patients who received radiation, at the time of 95 days (median postRT survival), $40 \%$ of patients still did not have any progression of dysphagia. This validates the use of RT as an effective method of palliation of dysphagia to ensure that most patients are able to swallow at least liquids and soft diet until the time of death.

Most patients who had stents inserted had worse DS at presentation which can be attributed to more advanced disease and possibly more aggressive tumour biology. Cumulatively, these factors could lead to decreased tumour response and control following palliative RT and hence account for the poorer response in all measured outcomes in the stented subgroup of patients in our study population. Other than DS and PS (ECOG), no other patient or tumour factors significantly affected the outcomes in our patients treated with palliative RT. As such, PS and DS at presentation can be used to guide patient selection for those who will benefit the most from palliative RT, which 
can be useful in the setting of limited resources. Additionally, the DS and mean objective change in DS after RT can also be used to determine which patients are likely to have a longer survival and hence may benefit from further palliative therapies.

A major problem in the developing countries such as our setting revolves around access to care and health education, resulting in a high proportion of patients presenting late with advanced stage disease. ${ }^{24}$ In our study, approximately $75 \%$ of patients reported having symptoms for more than three months and almost $10 \%$ of patients had symptoms for more than a year. Approximately $70 \%$ of patients presented had PS (ECOG) $\geq 2$ and more than $80 \%$ of patients presented had significant weight loss of more than $10 \%$ baseline body weight. This can be attributed to the advanced DS at presentation, with more than $90 \%$ of patients having a DS of at least grade 2. This affects nutritional status and PS (ECOG) and contributes to the poor general physical condition that precludes many oesophageal cancer patients from receiving radical treatment. ${ }^{6,7}$

When examining patient and disease characteristics, a male predominance is seen in our study $(54.8 \%)$, with a higher incidence of squamous cell cancer $(92.9 \%)$ and a predominance of tumours on the upper and middle oesophagus (70.3\%). Previous data report oesophageal cancers located in the upper oesophagus are primarily squamous cell cancers and are associated with lifestyle and cultural factors such as diet, smoking and heavy alcohol consumption ${ }^{25}$ and generally tend to be more prevalent in lower socio-economic populations. $^{2}$ These factors are also noted in a large proportion of our study population.

At our centre, the standard fractionation schedule used is 18.4 Gy in four fractions, which has the same EQD2 as 20 Gy in five fractions, a frequently used palliative fractionation schedule. ${ }^{26}$ Notably, the fractionation schedule did not impact the objective response to RT. This is of significance in low- and middle-income countries where resources are scarce as a shorter fractionation schedule (i.e. 18.4 Gy in four fractions) can improve the workflow. The acute toxicity and complication associated with this regimen from our experience are tolerable, however were not described in the study; and hence, further research is necessary for comparison in this regard to other fractionation schedules.

A limitation of our study was that the impact of RT on the other symptoms associated with locally advanced oesophageal cancer such as odynophagia, pain and regurgitation was not assessed. Existing data suggest benefits of radiation for palliation of these symptoms but the duration of response is unknown. ${ }^{27}$ In addition, an objective assessment of the DS was involved following RT; however, the impact on nutritional status and weight gain was not assessed. These represent areas requiring further work in locally advanced and metastatic oesophageal cancer.

\section{Conclusion}

Radiotherapy is beneficial to palliation of dysphagia associated with locally advanced and metastatic squamous cell cancer of the oesophagus with respect to DPFS and improvement in DS. The median duration of DPFS following RT was 73 days; in relation to the post-RT survival, this was effective in palliating dysphagia in approximately $60 \%$ of patients until the time of death. Patients who have stent insertions had a shorter duration of response compared to patients without stent insertions. In the setting of patients with locally advanced and metastatic oesophageal cancer who are receiving palliative treatment, PS (ECOG) and DS at presentation can be used as a surrogate to determine which patients will benefit the most from RT. A short course of RT can be an effective method of palliation in these patients in a limited resource setting. Additional investigations on the quality of life and impact of RT on relief of other symptoms may be beneficial to further quantify the magnitude of benefits in these patients.

\section{Acknowledgements}

The authors would like to acknowledge Marla Vina A. Briones, RMT, MSc. Epidemiology (Public Health) for her contribution to the statistical analysis.

\section{Competing interests}

The authors declare that they have no financial or personal relationships that may have inappropriately influenced them in writing this article.

\section{Authors' contributions}

N.B. was responsible for the literature research, data analysis and write up of the manuscript. N.B., V.B., A.H., G.C. and B.R. were responsible for reviewing the manuscript prior to submission.

\section{Funding information}

This research received no specific grant from any funding agency in the public, commercial or not-for-profit sectors.

\section{Data availability}

Raw data will be provided by corresponding author upon reasonable request.

\section{Disclaimer}

The views and opinions expressed in this article are those of the authors and do not necessarily reflect the official policy or position of any affiliated agency of the authors.

\section{References}

1. UK Cancer Research Esophageal Cancer Online. [cited 2020 Mar 05]. Available from: https://www.cancerresearchuk.org/

2. Torre LA, Bray F, Siegel RL, Ferlay J, Lortet-Tieulent J, Jemal A. Global cancer statistics, 2012. CA Cancer J Clin. 2015;65(2):87-108. https://doi.org/10.3322/caac.21262 
3. Registry SANC. Cancer in South Africa 2014 full report South Africa. 2014 [cited 2020 Mar 6]. Available from: https://www.cansa.org.za/files/2018/08/CancerRegsitry-2014.pdf

4. Dandara C, Robertson B, Dzobo K, Moodley L, Parker MI. Patient and tumour characteristics as prognostic markers for oesophageal cancer: A retrospective analysis of a cohort of patients at Groote Schuur Hospital. Eur J Cardiothorac Surg. 2016;49(2):629-634. https://doi.org/10.1093/ejcts/ezv135

5. Frenken M. Best palliation in esophageal cancer: Surgery, stenting, radiation, or what? Dis Esophagus. 2001;14(2):120-123. https://doi. org/10.1046/j.1442-2050.2001.00168.x

6. Anandavadivelan P, Lagergren P. Cachexia in patients with oesophageal cancer. Nat Rev Clin Oncol. 2016;13(3):185-198. https://doi.org/10.1038/nrclinonc.2015.200

7. Smyth EC, Lagergren J, Fitzgerald RC, et al. Oesophageal cancer. Nat Rev Dis Primers. 2017;3:17048. https://doi.org/10.1038/nrdp.2017.48

8. Daly JM, Fry WA, Little AG, et al. Esophageal cancer: Results of an American College of Surgeons patient care evaluation study. J Am Coll Surg. 2000;190(5): 562-572; discussion 72-73. https://doi.org/10.1016/S1072-7515(00)00238-6

9. Darling GE. Quality of life in patients with esophageal cancer. Thorac Surg Clin. 2013;23(4):569-575. https://doi.org/10.1016/j.thorsurg.2013.07.011

10. Amdal CD, Jacobsen AB, Guren MG, Bjordal K. Patient-reported outcomes evaluating palliative radiotherapy and chemotherapy in patients with oesophageal cancer: A systematic review. Acta Oncol. 2013;52(4):679-690. https://doi.org/10. 3109/0284186X.2012.731521

11. Prasad NR, Karthigeyan M, Vikram K, Parthasarathy R, Reddy KS. Palliative radiotherapy in esophageal cancer. Indian J Surg. 2015;77(1):34-38. https://doi. org/10.1007/s12262-013-0817-4

12. Dai Y, Li C, Xie Y, et al. Interventions for dysphagia in oesophageal cancer. Cochrane Database Syst Rev. 2014(10):CD005048. https://doi.org/10.1002/14651858. Database Syst
CD005048.pub4

13. Weigel TL, Frumiento C, Gaumintz E. Endoluminal palliation for dysphagia secondary to esophageal carcinoma. Surg Clin N Am. 2002;82(4):747-761. https://doi.org/10.1016/S0039-6109(02)00037-3

14. Rueth NM, Shaw D, D'Cunha J, Cho C, Maddaus MA, Andrade RS. Esophageal stenting and radiotherapy: A multimodal approach for the palliation of symptomatic malignant dysphagia. Ann Surg Oncol. 2012;19(13):4223-4228. https://doi.org/10.1245/s10434-012-2459-3

15. Siersema PD, Dees J, Van Blankenstein M. Palliation of malignant dysphagia from oesophageal cancer. Rotterdam Oesophageal Tumor Study Group. Scand J Gastroenterol Suppl. 1998;33(225):75-84. https://doi.org/10.1080/ 003655298750027272

16. Javed A, Pal S, Dash NR, et al. Palliative stenting with or without radiotherapy for inoperable esophageal carcinoma: A randomized trial. J Gastrointest Cancer. 2012;43(1):63-69. https://doi.org/10.1007/s12029-010-9206-4
17. Penniment MG, De leso PB, Harvey JA, et al. Palliative chemoradiotherapy versus radiotherapy alone for dysphagia in advanced oesophageal cancer: A multicentre randomised controlled trial (TROG 03.01). Lancet Gastroenterol Hepatol. randomised controlled trial (TROG 03.01). Lancet Gastroentero
2018;3(2):114-124. https://doi.org/10.1016/S2468-1253(17)30363-1

18. Caspers RJL, Welvaart K, Verkes RJ, Hermans J, Leer JWH. The effect of radiotherapy on dysphagia and survival in patients with esophageal cancer. Radiother Oncol. 1988;12(1):15-23. https://doi.org/10.1016/01678140(88)90188-0

19. Welsch J, Kup PG, Nieder $C$, et al. Survival and symptom relief after palliative radiotherapy for esophageal cancer. J Cancer. 2016;7(2):125-130. https://doi. org/10.7150/jca.13655

20. Knyrim K, Wagner HJ, Bethge $N$, Keymling M, Vakil N. A controlled trial of an expansile metal stent for palliation of esophageal obstruction due to inoperable cancer. New Engl J Med. 1993;329(18):1302-1307. https://doi.org/10.1056/ NEJM199310283291803

21. Bergquist $H$, Wenger $U$, Johnsson $E$, et al Stent insertion or endoluminal brachytherapy as palliation of patients with advanced cancer of the esophagus and gastroesophageal junction. Results of a randomized, esophagus and gastroesophageal junction. Results of a randomized,
controlled clinical trial. Dis Esophagus. 2005;18(3):131-139. https://doi. controlled clinical trial. Dis Esophagus.
org/10.1111/j.1442-2050.2005.00467.x

22. Homs MY, Steyerberg EW, Eijkenboom WM, et al. Single-dose brachytherapy versus metal stent placement for the palliation of dysphagia from oesophageal
cancer: Multicentre randomised trial. Lancet. 2004;364(9444):1497-1504. https://doi.org/10.1016/S0140-6736(04)17272-3

23. Shenfine J, McNamee P, Steen N, Bond J, Griffin SM. A pragmatic randomised controlled trial of the cost-effectiveness of palliative therapies for patients with inoperable oesophageal cancer. Health Tech Assess. 2005;9(5):iii, 1-121. https:// doi.org/10.3310/hta9050

24. Samiei M. Challenges of making radiotherapy accessible in developing countries. Cancer Care Emerg Health Syst. 2013:87-96.

25. Rahma OE, Greten TF, Duffy A. Locally advanced cancer of the esophagus, current treatment strategies, and future directions. Front Oncol. 2012;2:52. https://doi. org/10.3389/fonc.2012.00052

26. Adamson D, Blazeby J, Nelson A, et al. Palliative radiotherapy in addition to selfexpanding metal stent for improving dysphagia and survival in advanced oesophageal cancer (ROCS: Radiotherapy after Oesophageal Cancer Stenting): oesophageal cancer (ROCS: Radiotherapy after Oesophageal Cancer Stenting):
Study protocol for a randomized controlled trial. Trials. 2014;15(1):402. https:// Study protocol for a randomized contro
doi.org/10.1186/1745-6215-15-402

27. Deressa BT, Tigeneh W, Bogale N, Buwenge M, Morganti AG, Farina E. Shortcourse 2-dimensional radiation therapy in the palliative treatment of esophageal cancer in a developing country: A phase II study (Sharon Project). Int J Radiat Oncol Biol Phys. 2020;106(1):67-72. https://doi.org/10.1016/j. ijrobp.2019.10.004 


\section{Appendix 1}

TABLE 1-A1: Dysphagia score grading system

Grade

Grade 0

Grade 1

Grade 2

Grade 3

Grade 4

Source: Knyrim K, Wagner HJ, Bethge N, Keymling M, Vakil N. A controlled trial of an

expansile metal stent for palliation of esophageal obstruction due to inoperable

cancer. New Engl J Med. 1993;329(18):1302-1307. https://doi.org/10.1056/

NEJM199310283291803

escription

eat all solids/no dysphag

Able to eat only some solid foods

Able to eat only soft foods

Able to drink liquids only

Complete dysphagia 